\title{
Platelet 12-lipoxygenase and stem cells in Barrett's esophagus
}

\author{
KAZIMIERZ JAŚKIEWICZ ${ }^{1 *}$, EWA IŻYCKA-ŚWIESZEWSKA ${ }^{1}$, MARIA JANIAK ${ }^{2}$, \\ WIESŁAWA ŁYSIAK-SZYDŁOWSKA ${ }^{3}$, KRYSTIAN ADRYCH ${ }^{2}$, \\ JEANNETTE REINARTZ ${ }^{4}$, JERZY JANKUN ${ }^{3,5}$ and EWA SKRZYPCZAK-JANKUN ${ }^{5}$ \\ Departments of ${ }^{1}$ Pathology, ${ }^{2}$ Gastroenterology, and ${ }^{3}$ Clinical Nutrition, Medical University of Gdańsk, \\ Poland; ${ }^{4}$ American Diagnostica GmbH, D-64319 Pfungstadt, Germany; ${ }^{5}$ Department of Urology, \\ The University of Toledo, Toledo, OH 43614, USA
}

Received May 5, 2010; Accepted June 23, 2010

DOI: 10.3892/ol_00000137

\begin{abstract}
Esophageal adenocarcinoma has shown a significant increase in incidence in recent years. It is thought that the development of gastroesophageal reflux disease (GERD), followed by columnar-lined esophagus and the development of dysplasia, leads to invasive adenocarcinoma. The exact pathogenesis of this process, the diagnosis and differentiation of the metaplastic and dysplastic esophageal lesions have yet to be determined. The purpose of this immunohistochemical study was to investigate the expression of pro-tumorigenic enzyme platelet 12-lipoxygenase (p12LOX) using two new available antibodies in non-dysplastic and dysplastic Barrett's esophagus. The stem cell markers nestin, CD117 and CD44, were then evaluated. The comparative group included GERD carditis, gastric intestinal metaplasia and colorectal adenoma. The overexpression of p12LOX detected by two specific antibodies in the non-dysplastic and dysplastic Barrett's mucosa clearly demonstrated that this enzyme plays an important role in the development of esophageal adenocarcinoma.
\end{abstract}

\section{Introduction}

Cases of adenocarcinoma in Barrett's esophagus (BE) are on the increase in Western countries. Clinical and histological studies suggest a successive progression from gastroesophageal reflux disease (GERD) to columnar-lined esophagus, also known as BE, to dysplasia with a high risk of malignancy. The pathogenesis of this sequence has yet to be completely elucidated, since more cases of BE, dysplasia and adenocarcinoma were recently found among patients without GERD symptoms than those that underwent endoscopy because of GERD (1).

Correspondence to: Dr Ewa Skrzypczak-Jankun, Department of Urology, The University of Toledo, Toledo, OH 43614, USA

E-mail: ewa.skrzypczak-jankun@utoledo.edu

*Deceased

Key words: Barrett's esophagus, lipoxygenase 12, CD44, CD117, nestin
This result depends on the identifying criteria indicative for BE used by the endoscopist who obtains the biopsy. The management of BE remains controversial. Various guidelines exist and the international consensus over issues, such as recognition of short-segment disease and surveillance policies for uncomplicated and dysplastic disease, is lacking (2).

The histological diagnosis of $\mathrm{BE}$ involves the presence of columnar epithelium with goblet cells in the esophageal mucosa. Dysplasia-intraepithelial neoplasia (IEN) serves as a morphological marker for increased cancer risk. The most important diagnostic markers of IEN are poor maturation, excessive crowding of glands and cytonuclear features. It is believed that the development of $\mathrm{BE}$ with intestinal goblet-type cells is related to the process of proliferation and differentiation of pluripotential epithelial stem cells in response to local injury, chronic inflammation as well as the repair process being altered (3-5). The practical utility of mucin stainings, endocrine cell count, assessment of cell proliferation (Ki-67 and PCNA), expression of EGF, TGF $\alpha$ and p53 is limited regarding the diagnosis and differentiation of dysplastic and non-dysplastic BE $(6,7)$.

One of the factors related to esophageal adenocarcinoma pathogenesis is an aberrant arachidonic acid (AA) metabolism through cyclooxygenase (COX) and 5- and 12-lipooxygenase (5- and 12-LOX). Numerous published studies are related to the expression of stem cell markers and pro-tumorigenic enzymes 5- and 12-LOX in BE. Findings of these studies showed a positive expression in esophageal adenocarcinoma, with inconsistent results in other lesions of esophago-gastric junction mucosa $(4,8,9)$. This study aimed to assess platelet 12-lipoxygenase (p12LOX) and stem cell markers in BE mucosa and other gastro-intestinal mucosal lesions.

\section{Materials and methods}

Patients. Between 2005 and 2007, endoscopical biopsies were obtained from 110 patients, aged 33-71 years, with a clinical and endoscopical diagnosis of GERD and the suggestion of BE, in the Department of Gastroenterology, Medical University of Gdańsk, Poland. The pathological examination of gastro-esophageal junction biopsies performed by two independent pathologists confirmed the initial diagnosis in 19 cases. Of the immunohistochemical examinations performed in the $\mathrm{BE}$ cases, 5 of $\mathrm{BE}$ 
Table I. The positive immunoreactivity of p12LOX, CD44 and nestin in Barrett's metaplasia, GERD carditis and colorectal adenomas.

\begin{tabular}{lcccrr}
\hline Antibodies & No. of patients & $\begin{array}{c}\text { p12LOX } \\
\text { ab7212 }\end{array}$ & $\begin{array}{c}\text { p12LOX } \\
\text { ab7225 }\end{array}$ & CD44 & Nestin \\
Barrett's mucosa & 19 & 19 & 18 & 11 & 10 \\
Barrett's dysplasia & 5 & 5 & 5 & 5 & 5 \\
Gastric carditis & 10 & 3 & 3 & 1 & 1 \\
Gastric intestinal metaplasia & 17 & 3 & 1 & 3 & 3 \\
Colorectal adenoma & 10 & 7 & & & 0 \\
\hline
\end{tabular}

GERD, gastroesophageal reflux disease.
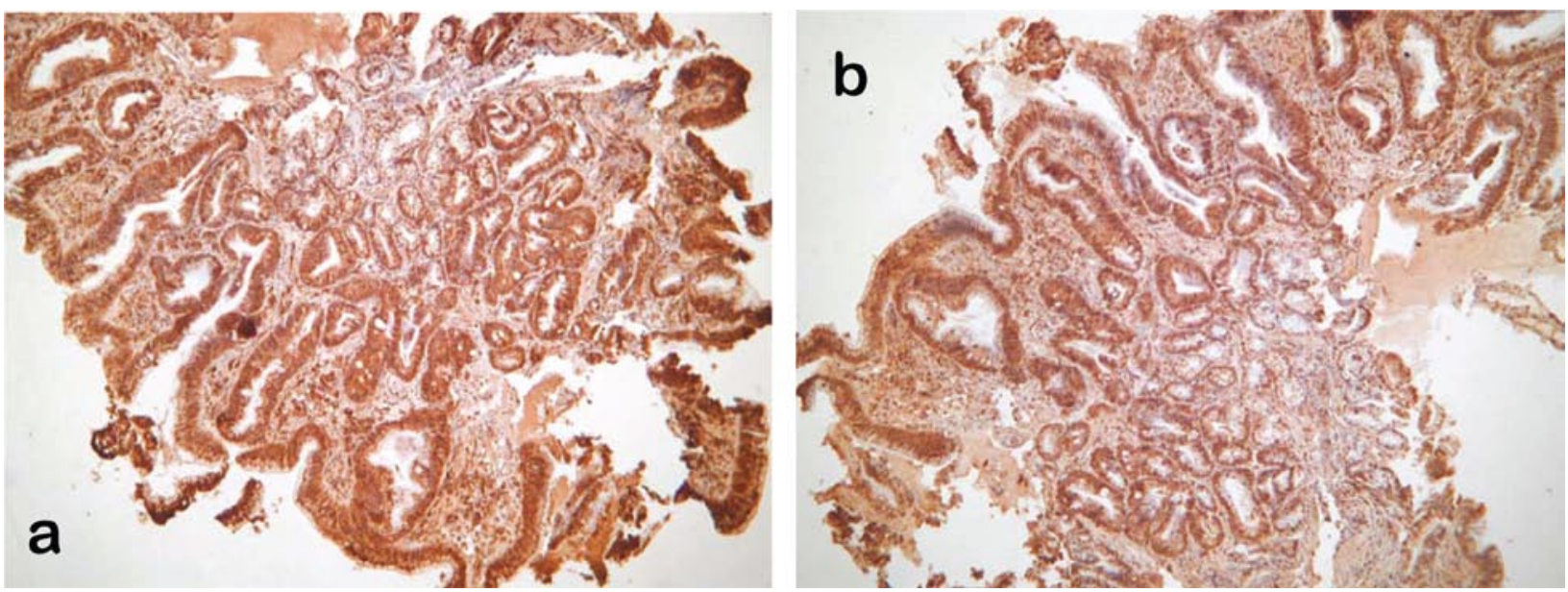

Figure 1. Strong immunostaining for 12-LOX with (a) ab7212 and (b) CD44 in Barrett's mucosa.

with low-grade dysplasia, 10 of endoscopically suggested BE without pathological confirmation (gastric carditis), 17 of gastric mucosal intestinal metaplasia and 10 of sporadic colorectal lowgrade adenomas were included in the study.

Antibodies and proteins. The p12LOX antibodies were developed based on whole-length recombinant human enzyme with 7212 being rabbit, polyclonal and 7225 murine, monoclonal, anti-human antibodies (American Diagnostica, Inc.; clones 12.05 and 25.20 , dilution 1:200 and 1:300, respectively). The new antibodies were checked for cross-reactivity against all human lipoxygenases. The recombinant enzymes, except for p12LOX from our laboratory (5), were generous donations from Dr T. Holman, University of California, Santa Cruz, CA, USA (5LOX, 15LOX-1 and 15LOX-2), and Dr A. Brash, Vanderbilt University Medical Center, Nashville, TN, USA (12R-LOX and eLOX3). The antibodies for nestin (196908, 1:50), CD44 (M7082, 1:50) and CD117 (K4011, 1:400) used in this study were from Dako, Dakopatts, Denmark. The tissues of gastric adenocarcinoma were used for the positive controls.

Immunohistochemistry. Paraffin-embedded tissue blocks were available for immunohistochemical evaluation in all 110 cases. Standard avidin-biotin-peroxidase complex technique was used for immunohistochemistry performed on $4-\mu \mathrm{m}$ paraffin sections of formalin-fixed, paraffin-embedded tissue. Antigen retrieval in heated citrate buffer at $\mathrm{pH} 6.0$ with an incubation time of $30 \mathrm{~min}$ was applied to the antibodies. The immunoreactivity was scored on a 3-point scale, with $1+$ (low) reactivity in $<10 \%$ of the epithelial cell population, $2+$ (moderate) in $10-40 \%$ of cells and $3+$ (high) in $>40 \%$ of cells.

\section{Results}

The immunoreactivity of the tested antibodies varied. Stem cell marker CD117 was completely negative. The positive immunoreactivity of the remaining antibodies is collated in Table I. The majority of the cases of Barrett's mucosa showed moderate to high immunoreactivity with p12LOX antibodies (Fig. 1a) and more than half of the cases were immunopositive for stem-cell antibodies CD44 (Fig. 1b) and nestin. The highest immunoreactivity was observed in dysplastic BE mucosa. The 5 cases of Barrett's with IEN showed high positive immunoreactivity with p12LOX, CD44 and nestin antibodies.

In the comparative group, few clinically suspicious cases not morphologically confirmed for BE showed mild focal immunopositive reactions. A total of 3 of 17 cases in the gastric mucosal intestinal metaplasia cases showed focal immunopositivity for the tested markers restricted to the foci of low-grade mucosal dysplasia. The majority of the colorectal adenomas 
with low-grade dysplasia showed mild positive immunostaining for p12LOX ab7212 (rabbit, polyclonal), whereas p12LOX ab7225 (murine, monoclonal) was positive in only 1 case with negative stem cell markers.

\section{Discussion}

The diagnostic incidence of BE in the endoscopical biopsy material obtained from the OG junction mucosa of patients with GERD, endoscopically suspected for BE, (13\%) is comparable to the incidence reported by other studies $(1,10)$. Our diagnostic criteria of BE and lesions suggestive for GERD gastric carditis are the same as those of Montgomery (10).

Lipoxygenases (LOXs) are significant enzymes that metabolize AA to hydroxyl-eicosatetraenoic acids (HETE) and leukotrienes involved in inflammatory and carcinogenic processes. Platelet 12-LOX metabolite 12S-HETE affects cell proliferation and apoptosis on the signal transduction pathway mediated by ERK (11). Limited information related to the role and expression of LOX in BE is currently available. 5-LOX showed immunohistochemical overexpression during esophageal adenocarcinogenesis (12). 5- and 12-LOX are regarded as pro-tumorigenic enzymes in colonic carcinogenesis and their overexpression was also described in various types of cancer [(13-16) and references therein]. The new antibodies developed for this study were the first on the market with specificity for the whole-length enzyme and with proven lack of any crossreactivity with other human LOXs. Our studies have shown the usefulness of these new antibodies for immunohistochemical studies of parafin-embedded samples in melanoma, prostate, uteral and kidney cancers (data not shown) in addition to the gastrointestinal samples discussed in this study.

Our findings showed extremely high immunoreactivity of the two p12LOX antibodies in non-dysplastic BE and Barrett's dysplasia, thereby confirming the pro-carcinogenic activity of platelet 12-LOX and suggesting the diagnostic utility of the two antibodies in GERD and BE.

CD44 is a cell surface molecule enrolled in cell-cell and cell-extracellular matrix protein interactions. In particular, its spliced variants 5 and 6 have been shown to play a role in the progression of certain tumors, including gastric carcinoma. According to Menges et al (9), the expression of CD44 noted in Barrett's carcinoma did not increase compared to nondysplastic BE and was completely negative in gastric mucosa. Other investigators $(8,17)$ showed that CD44 progressively increases in Barrett's dysplasia and adenocarcinoma.

Stem cell markers CD44 and nestin, as shown in our study, are potential markers of malignant transformation in $\mathrm{BE}$, similar to intestinal metaplasia of the stomach $(17,18)$. Our study results also showed that p12LOX and stem-cell immunoreactivity is much higher in $\mathrm{BE}$ when compared to other gastrointestinal mucosal cancer precursor lesions and suggests a more active pre-neoplastic transformation of Barrett's mucosa.

\section{Acknowledgements}

The authors wish to thank American Diagnostica, Inc., for providing p12LOX antibodies and Dr R. Hart for the financial support (to J.J. and E.S.J.) of our research. This work was financed in part by The Frank D. Stranaham Endowment Fund for Oncological Research and The Frederick M. Douglass Foundation. In memory of Professor K. Jaśkiewicz (pathologist), who was instrumental in this research and passed away.

\section{References}

1. Fan X and Snyder N: Prevalence of Barrett's esophagus in patients with or without GERD symptoms: role of race, age, and gender. Dig Dis Sci 54: 572-577, 2009.

2. Ramus JR, Caygill CP, Gatenby PA and Watson A: Current United Kingdom practice in the diagnosis and management of columnar-lined oesophagus: results of the United Kingdom National Barrett's Oesophagus Registry endoscopist questionnaire. Eur J Cancer Prev 17: 422-425, 2008.

3. Guillem PG: How to make a Barrett esophagus: pathophysiology of columnar metaplasia of the esophagus. Dig Dis Sci 50: 415-424, 2005.

4. Hattori T, Mukaisho K and Miwa K: [Pathogenesis of Barrett's esophagus - new findings in the experimental studies of duodenal reflux models]. Nippon Rinsho (in Japanese) 63: 1341-1349, 2005.

5. Tang LH and Klimstra DS: Barrett's esophagus and adenocarcinoma of the gastroesophageal junction: a pathologic perspective. Surg Oncol Clin N Am 15: 715-732, 2006.

6. Jaskiewicz K, Louw J and Anichkov N: Barrett's oesophagus: mucin composition, neuroendocrine cells, p53 protein, cellular proliferation and differentiation. Anticancer Res 14: 1907-1912, 1994.

7. Rustgi AK: Models of esophageal carcinogenesis. Semin Oncol 33: S57-S58, 2006.

8. Lagorce-Pages C, Paraf F, Dubois S, Belghiti J and Flejou JF: Expression of CD44 in premalignant and malignant Barrett's oesophagus. Histopathology 32: 7-14, 1998.

9. Menges M, Goebel R, Pueschel W, Zeitz M and Stallmach A: Expression of CD44v5 and -v6 in Barrett's carcinoma is not increased compared to that in nondysplastic Barrett's mucosa. Exp Mol Pathol 72: 207-212, 2002.

10. Montgomery EA: Biopsy Interpretation of Gastrointestinal Tract Mucosa. Lippincott Williams \& Wilkins, pp37-70, 2005.

11. Chen FL, Wang XZ, Li JY, Yu JP, Huang CY and Chen ZX: 12-lipoxygenase induces apoptosis of human gastric cancer AGS cells via the ERK1/2 signal pathway. Dig Dis Sci 53: 181-187, 2008.

12. Chen $\mathrm{X}$, Wang $\mathrm{S}, \mathrm{Wu} \mathrm{N}$, et al: Overexpression of 5-lipoxygenase in rat and human esophageal adenocarcinoma and inhibitory effects of zileuton and celecoxib on carcinogenesis. Clin Cancer Res 10: 6703-6709, 2004.

13. Bednar W, Holzmann K and Marian B: Assessing 12(S)lipoxygenase inhibitory activity using colorectal cancer cells overexpressing the enzyme. Food Chem Toxicol 45: 508-514, 2007.

14. Gong Z, Hebert JR, Bostick RM, et al: Common polymorphisms in 5-lipoxygenase and 12-lipoxygenase genes and the risk of incident, sporadic colorectal adenoma. Cancer 109: 849-857, 2007.

15. Hoque A, Lippman SM, Wu TT, et al: Increased 5-lipoxygenase expression and induction of apoptosis by its inhibitors in esophageal cancer: a potential target for prevention. Carcinogenesis 26 : 785-791, 2005.

16. Skrzypczak-Jankun E, Chorostowska-Wynimko J, Selman SH and Jankun J: Lipoxygenases - a challenging problem in enzyme inhibition. Current Enzyme Inhibition 3: 119-132, 2007.

17. Castella E, Ariza A, Fernandez-Vasalo A, Roca $X$ and Ojanguren I: Expression of $\mathrm{CD} 44 \mathrm{H}$ and $\mathrm{CD} 44 \mathrm{v} 3$ in normal oesophagus, Barrett mucosa and oesophageal carcinoma. J Clin Pathol 49: 489-492, 1996.

18. Gulmann C, Grace A, Leader M, Butler D, Patchett S and Kay E: CD44v6: a potential marker of malignant transformation in intestinal metaplasia of the stomach? An immunohistochemical study using tissue microarrays. Eur J Gastroenterol Hepatol 15: 981-986, 2003. 